\title{
A smart wearable device based on internet of things for the safety of children in online transportation
}

\author{
Elsyea Adia Tunggadewi, Eva Inaiyah Agustin, Riky Tri Yunardi
}

Department of Engineering, Faculty of Vocational Studies, Airlangga University, Indonesia

\begin{tabular}{|c|c|}
\hline Article Info & ABSTRACT \\
\hline Article history: & \multirow{10}{*}{$\begin{array}{l}\text { The world needs to pay attention to children who often become victims of } \\
\text { violence and cannot escape social problems. Various safety devices that are } \\
\text { commonly known as smart wearable devices have been created, but they still } \\
\text { have many shortcomings. Thus, in this research a safety device that can be } \\
\text { held by children is designed and is equipped with a button that can be } \\
\text { pressed, then it will automatically send the location and photo of the scene to } \\
\text { the parent's cellphone via the telegram application. It uses the raspberry pi } \\
\text { zero W controller, the GNSS HMC5983 SAW LNA GPS Module to } \\
\text { determine the location, and the 5MP raspberry Pi Zero camera module to } \\
\text { capture the incident. Based on the results, the average time needed to share } \\
\text { locations is } 0.91 \text { seconds, and the average time needed to capture is } 11.57 \\
\text { seconds, if the device and receiving cellphone use the same network. } \\
\text { Additionally, the average time needed to share locations is } 0.96 \text { seconds, and } \\
\text { the average time needed to capture is } 12.09 \text { seconds, if the device and } \\
\text { receiving cellphone use a different network. Both conditions have } 97.5 \% \\
\text { location accuracy rate and } 100 \% \text { poto accuracy rate }\end{array}$} \\
\hline Received Sep 30, 2020 & \\
\hline Revised Mar 22, 2021 & \\
\hline Accepted Mar 30, 2021 & \\
\hline Keywords: & \\
\hline Camera & \\
\hline GPS & \\
\hline IoT & \\
\hline Raspberry Pi & \\
\hline Smart wearable device & \\
\hline
\end{tabular}

This is an open access article under the CC BY-SA license.

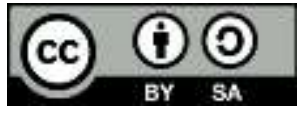

Corresponding Author:

Elsyea Adia Tunggadewi

Department of Engineering

Faculty of Vocational Studies

Airlangga University, Jl. Srikana No. 65 Surabaya, 60286, Indonesia

Email: elsyea-adia-tunggadewi@ vokasi.unair.ac.id

\section{INTRODUCTION}

Children have experienced a great deal of violence and abuse [1]-[4] in public places [1], [3], [4], on online, public transportation [3], and in the workplace [4]. This occurs because children are seen as weak objects who are often targeted in criminal acts, resulting in feelings of worry for those who want to go out of the house [1]-[3]. Until now, the main actions and efforts to maintain the safety of children are still minimal, such as by socializing, making laws [2] and making safety equipment for them [2], [3], [5]-[9].

The latest technologies that are widely used for a variety of safety devices include the internet of things (IoT) [5]-[7], global positioning systems (GPS) [3], [4], [8]-[9], and radio frequency identification (RFID) [9]. However, in general, users still need a long time to use them [8], have to go through several stages, and the existing safety devices are not equipped with cameras to find out the faces of the perpetrators of violence [2]-[4], and are not designed to used in online transportations.

The safety tools for children that have been created in recent decades include smart shoes [2], [7], smart rings [3], smart bracelets [8], which they can wear at any time and outside the house [2], [3], [7], [8], which we usually know as smart wearable devices. Several research has shown that these safety tools are of good quality [3]-[6], but there has been no research on children's safety equipment that is cheaper, user friendly, small, disguised, and available to use in online transportation. There is also no research using 
technology internet of things, the concept by which certain objects have the ability to transfer data [10]-[20] and is equipped with GPS for sharing location [21], as well as a camera for capturing images around [22].

In previous research [2], the smart shoe uses a GPS and GSM module, which can work together to send locations to the family, and the raspberry Pi-3 whose main control is the Arduino Uno, equipped with a camera to record what happened. All devices are mounted on the sole of the shoe, using a 5 Volt battery connected in series with a piezoelectric sensor. In this device [2], when a woman is in danger, she must immediately press the button on her shoe by stomping her foot. Once the button is pressed, there will be an active voltage that can be used to provide a shock voltage of $400 \mathrm{KV}$ to the perpetrator, then simultaneously, the GPS and GSM modules are activated with the help of Arduino Uno. The GPS module will calculate the location by detecting the latitude and longitude position, while the GSM module will send the location of the victim, as well as a link that contains a video that can identify the perpetrator [2]. This tool is very flexible and easy to use by children, but it is not suitable for use in online transportation because the shock voltage in the legs will be difficult to use when we are in a vehicle, and it requires space and energy to press the shoes firmly when the victim is sitting [2].

The use of GPS and GSM technology, as well as the raspberry Pi, is also carried out on smart rings for women's safety [3]. In addition, this research adds a newer technology, namely the internet of things (IoT). Technological advances have paved roads in almost all sides of life. Therefore, applying IoT to solve problems must be utilized properly and wisely. In this research, safety tools for children have applied IoT technology [3], [23]. IoT is an ecosystem that connects objects that can be accessed via the internet [3]. In general, IoT is expected to be able to provide good connections for devices, systems and machine-to-machine (M2M) communication services [3]. IoT can be applied to various activities in everyday life. The main purpose of the smart ring system is to identify locations instantly and send messages of assistance via the android application to registered contacts or the police, so that incidents are expected to be prevented in a quick time [3]. The advantage of this smart ring is that it is simple and economical and easy to use [3], but this application is only compatible with the android OS on a smart phone.

The popular IoT is also used in the manufacture of this smart device [5], [24]-[28], combining it with the Hidden Markov Model, and utilizing GPS and GSM to transmit locations. The IoT model used is classified into three layers [5], namely, the perception layer, the network layer, and the application layer. Perception layer consists of two sublayers, namely the data acquisition layer and the access layer. The network layer consists of the network application layer and the network transmission layer. The application layer consists of an execution layer and a radiator layer node, where each layer has its own function and task. HMM basically represents a bayesian to gather information with little possible data [5]. In other words, HMM can be said to be an algorithm that can identify threats based on visual or verbal displays [5], but the weakness of this designed system is in shooting which takes about three minutes.

In the previous research, there were also those who developed children's safety devices using GPS and GSM modules. Systems with RFID are good compared to simple technology [9], but this system still has many shortcomings, namely not using the latest technology, many errors identification, signal interference, and quite expensive costs [9], and not suitable to be used as a safety tool for children in online transportation.

In this research, a system was developed to correct the deficiencies that existed in previous research. The system in this tool will be used by students and children who can use online transportation by themselves, from 4 years old to 18 years old, according to the definition from WHO that a child is someone under 19 years of age. This system uses IoT as the latest technology that has never been used in children safety equipment in online transportation, but it will be able to provide a relatively cheaper cost, and easier to use for children because only a little knowledge is needed, namely pressing a button on the device in an emergency to send the location and images to the parent's telegram application. In this case the telegram ID is inputted into the system, so the tool will send the location and photos to the telegram ID according to what has been entered into the database. Also, the safety equipment already has its own name, called "Monitor Anak", so it can be ascertained that there is little chance of sending fake locations and photos. This system has a fairly good speed compared to existing tools.

In the process of working on this device, there are several steps that have been carried out. First, it started from system design and modeling, then it was continued with making a telegram ID database on the system. Finally, testing and analysis was carried out starting from making tools, testing controllers in the form of Raspberry Pi that had been designed, testing camera and GPS, sending the results of camera and GPS tests to the phonecell, testing IoT as the latest technology, to testing the success of the whole system.

\section{RESEARCH METHOD}

In this research, the study procedure to develop the proposed device was to identify children's problems in online transportation that have occurred frequently. Then plan the tools to be made, and then 
explain the purpose of making this tool is for the safety of children. Then design and make the device, then tested and evaluated, and the last is implemented as shown in Figure 1.

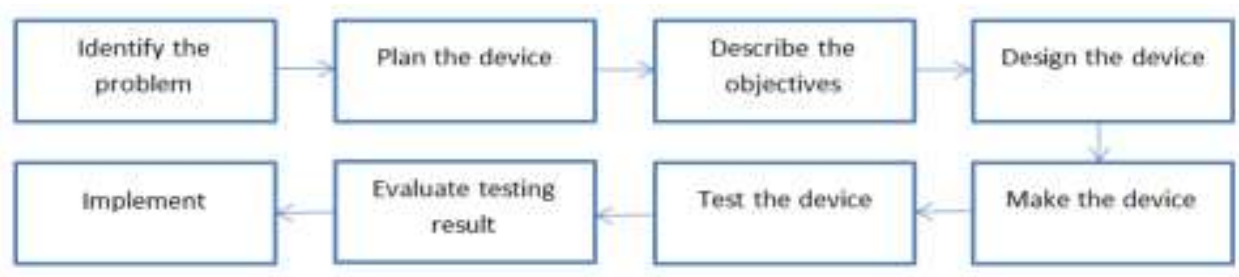

Figure 1. Study procedure of developing device

The working principle of this system is that if children who are in online transportation get a dangerous situation, they will press a button on the device, then send an input signal to the controller in the form of a Raspberry Pi [29], using the latest technology, namely IoT. Then, the camera on the device will automatically capture the photo of the perpetrator's face. At the same time, the GPS module will also send the coordinates to the ID telegram that has been created in the database. The input signal that enters the Raspberry Pi control will be forwarded to the server, and the captured image will be detected and once detected, the camera will capture the photo, and the photo will be forwarded to the parent's cellphone, via the telegram application as shown in Figure 2. Figure 3 shows an illustration of a device that sends a signal to the Raspberry Pi which will be forwarded to the parent's cellphone.

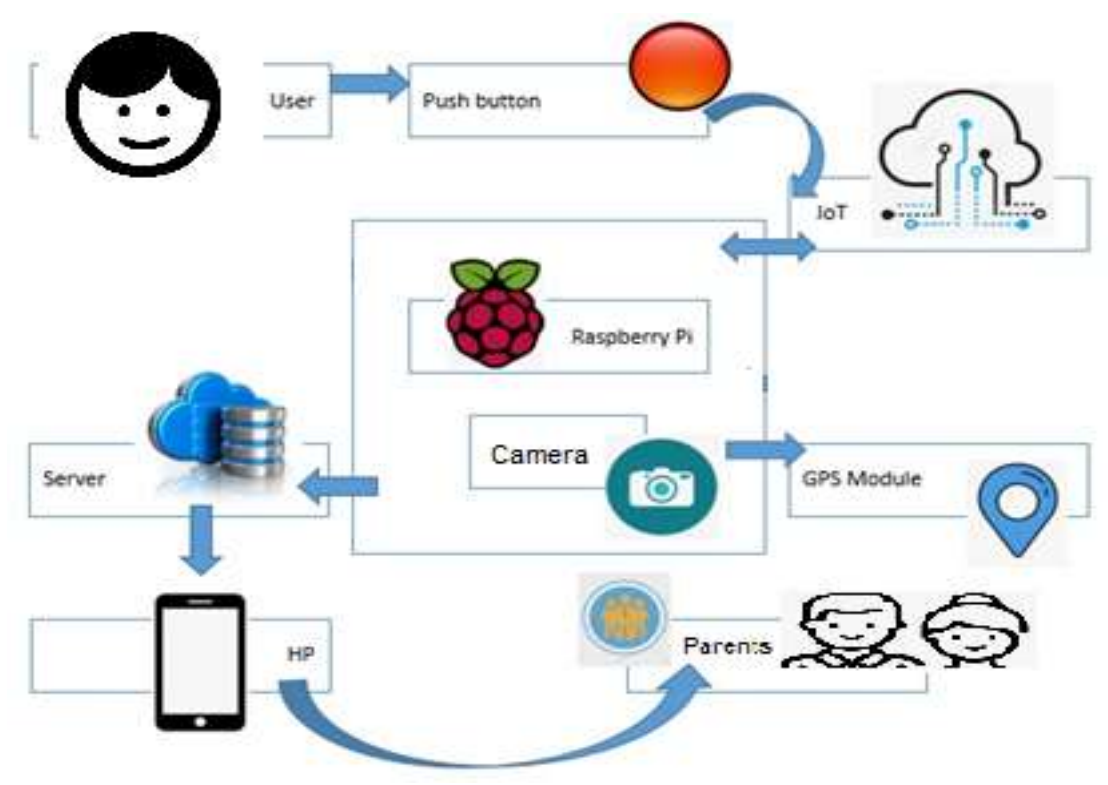

Figure 2. Block diagram of tools for children's safety in online transportation

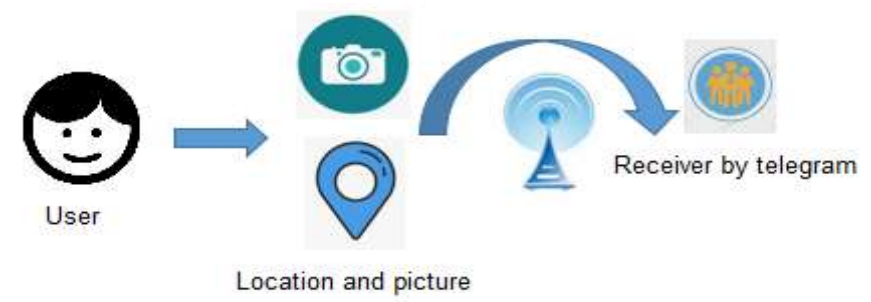

Figure 3. Illustration of a device that sends a signal to the raspberry Pi 
The button used is a push button that is suitable for the raspberry Pi as a controller. The raspberry Pi used in this tool is the Raspberry Pi Zero W, equipped with a GPS U Blox NEO module and a 5MP Camera module. The hardware configuration between the Raspberry Pi and the push button, GPS module and camera module is shown in Table 1.

After all the hardware is integrated, the next step is to activate the camera from the device configuration by selecting the interfacing option, followed by P1 Camera and Yes. Then, the camera is ready to get the photo. After that, we activate the GPS module on the Raspberry Pi until all the processes complete. The process of testing the tool is shown in Figure 4. The first one is the process of pressing the button on the tool. When the button is pressed, there will be a "beep" sound, this indicates that the button was successfully pressed. Then the yellow LED will flash, which is a sign that the GPS module is detected properly and is ready to send the location to the cellphone via the telegram application. Then the red LED light on the camera will light up, which indicates that the camera is detected properly and is taking pictures that will be sent to the receiving cellphone. In this research, data retrieval is carried out 10 times for location delivery and 10 times for image sending using 10Mbps data speed with 2 different networks. Then, on the device, 10 recipient telegram IDs are inserted, but sending the location and images are carried out alternately one by one.

Table 1. The hardware configuration

\begin{tabular}{ccc}
\hline Pin Raspberry & & Connected to \\
\hline 5V & Module GPS & VCC \\
GND & & GND \\
GPIO14 & & TXD \\
GPIO15 & RXD \\
GND & Push Button & Negative \\
GPIO26 & Module Camera & Positive \\
Camera Slot & & Pi Camera \\
\hline
\end{tabular}

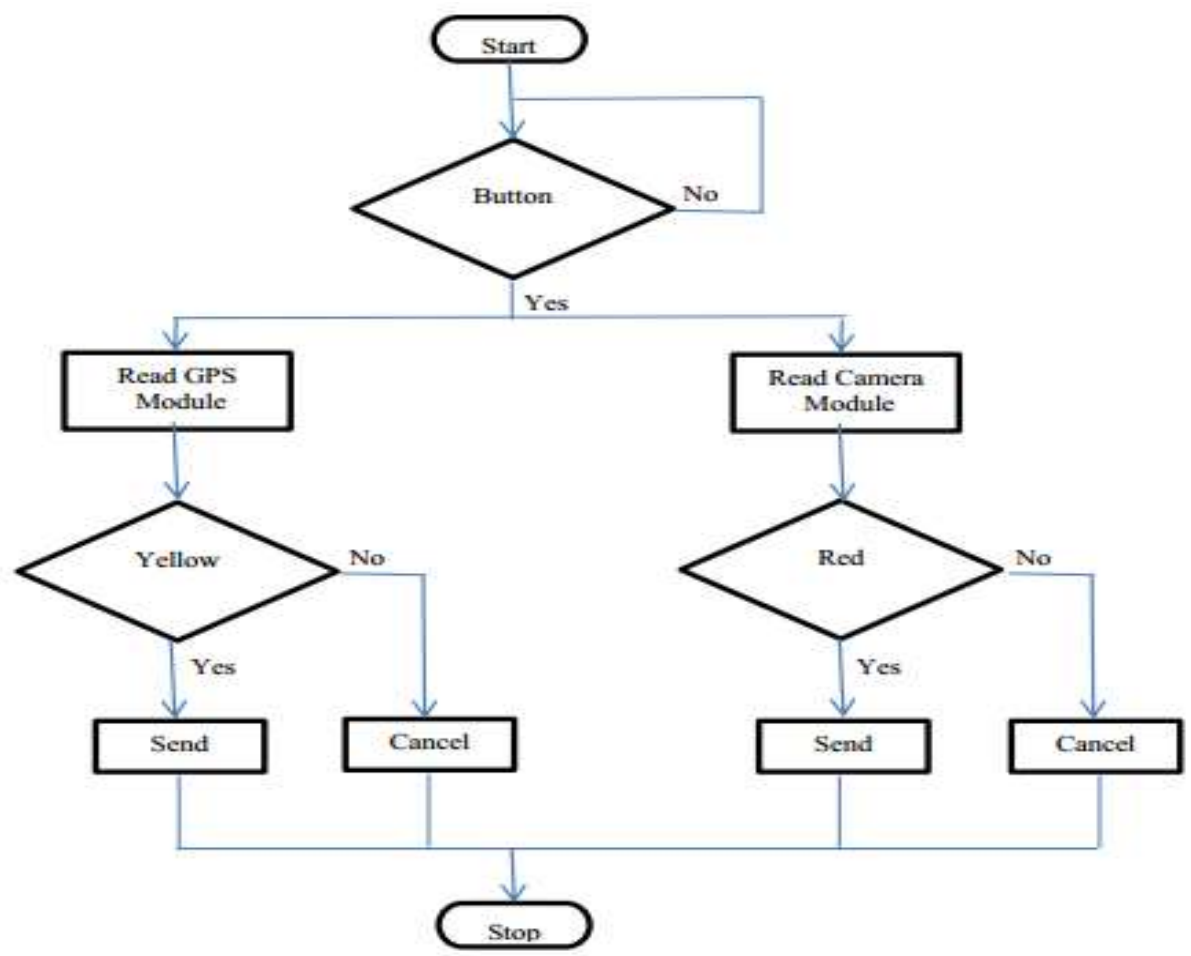

Figure 4. Testing process

\section{RESULTS AND ANALYSIS}

In the research that has been carried out, the details of the tool are shown in Figure 5, with the size of the tool $8 \mathrm{~cm} \times 3.5 \mathrm{~cm} \times 1.5 \mathrm{~cm}$, which is packed into a box measuring $15 \mathrm{~cm} \times 10 \mathrm{~cm} \times 7 \mathrm{~cm}$ as shown in Figure 6. The installation of a camera and buttons on the back is shown in Figure 7. 


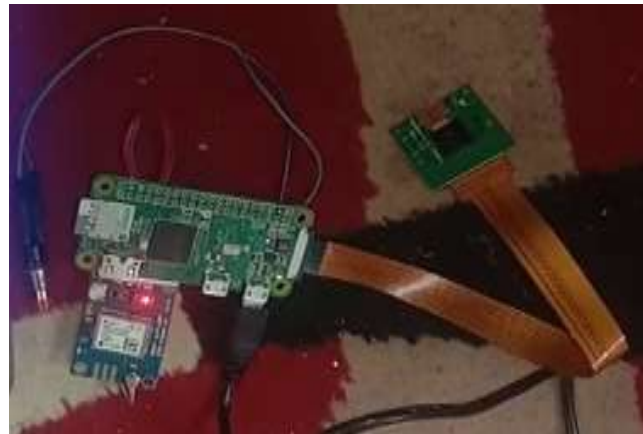

Figure 5. Details of child safety equipment in online transportation

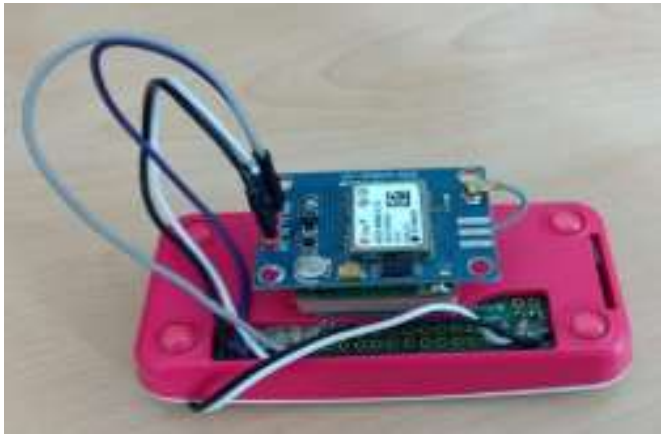

Figure 6. Child safety tools in online transportation

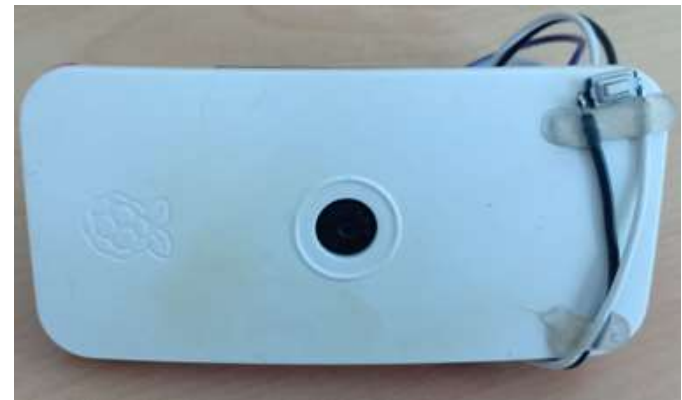

Figure 7. Camera and push button on the back

The tool that has been tried is shown in Figure 8, which will display the child's location at that time it is sent to the parent's cellphone via the telegram application. Then it continues by sending the person's photo which has been captured by the camera as shown in Figure 9.

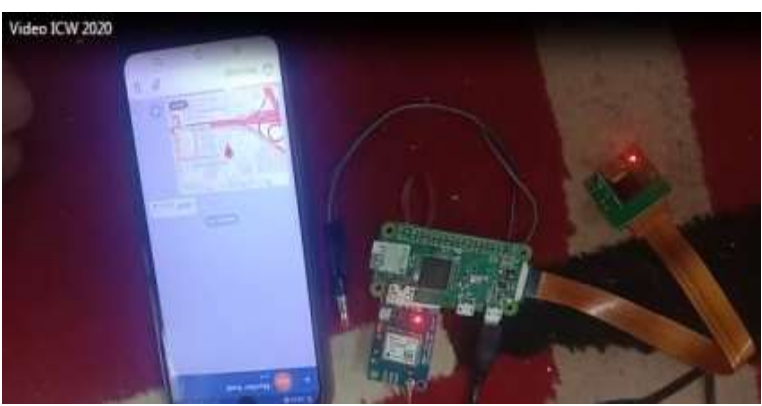

Figure 8. The location is sent to the recipient's cellphone via the telegram application

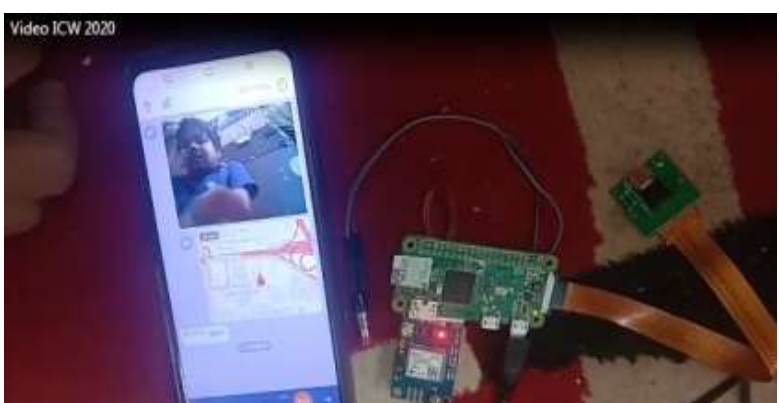

Figure 9. The photo is sent to the recipient's cellphone via the telegram application

In Figure 10 you can see a screenshot of the telegram application, where the location and photo will be visible in this application. It can be seen in Table 2 that this research was tried 10 times by pressing the button, and the results showed that all 10 trials were successful in sending locations 10 times, and in sending images also 10 times. Table 3 shows the results of the length of time taken to send the location to the recipient after pressing the button, using the same network between device and the receiving cellphone. The average result of admission time for 10 trials was 0.91 seconds. Meanwhile, Table 4 shows the results of the length of time to send photos to the recipient after pressing the button, using the same network between device and the receiving cellphone. The average result of admission time for 10 trials is 11.57 seconds. 


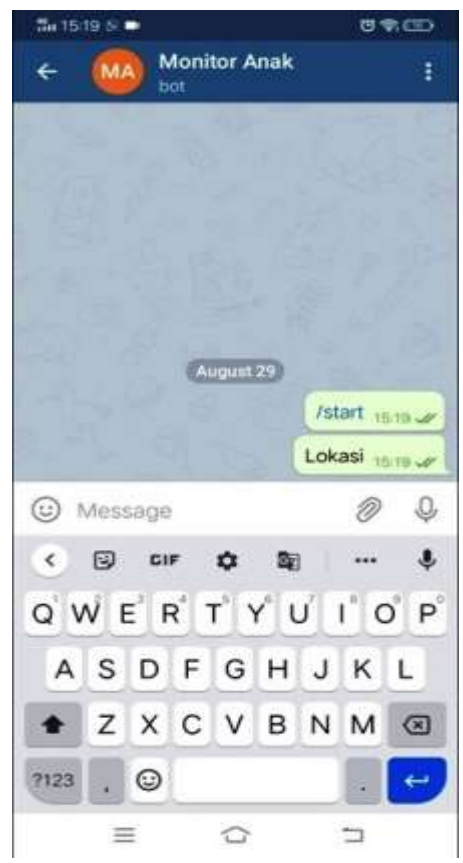

Figure 10. Telegram screenshot of child safety equipment in online transportation

Table 2. Experiment results to show the success of location and figure acceptance

\begin{tabular}{ccccc}
\hline Experimen & Sending Location & Sending Images & \multicolumn{2}{c}{ Success Rate (\%) } \\
& & & Sending Location & Sending Image \\
\hline 1 & OK & OK & 100 & 100 \\
2 & OK & OK & 100 & 100 \\
3 & OK & OK & 100 & 100 \\
4 & OK & OK & 100 & 100 \\
5 & OK & OK & 90 & 100 \\
6 & OK & OK & 90 & 100 \\
7 & OK & OK & 100 & 100 \\
8 & OK & OK & 100 & 100 \\
9 & OK & OK & 95 & 100 \\
10 & OK & OK & 100 & 100 \\
\multicolumn{2}{l}{ The average of success rate } & & 97,5 & 100 \\
\hline
\end{tabular}

Table 3. Experiment results to show the length of time needed by telegram when receiving locations using the same network between device and the receiving cellphone

\begin{tabular}{cc}
\hline Experiment & Time (second) \\
\hline 1 & 0.94 \\
2 & 0.96 \\
3 & 0.88 \\
4 & 0.89 \\
5 & 0.89 \\
6 & 0.88 \\
7 & 0.90 \\
8 & 0.94 \\
9 & 0.92 \\
10 & 0.90 \\
The average time of location & 0.91 \\
\hline
\end{tabular}

Table 4. Experiment results to show the length of time needed by telegram when receiving images using the same network between device and the receiving cellphone

\begin{tabular}{cc}
\hline Experiment & Time (second) \\
\hline 1 & 11.90 \\
2 & 11.80 \\
3 & 11.00 \\
4 & 11.51 \\
5 & 11.90 \\
6 & 11.76 \\
7 & 11.86 \\
8 & 11.31 \\
9 & 11.56 \\
10 & 11.06 \\
The average time of location & 11.57 \\
\hline
\end{tabular}

In the Table 5 and Table 6, the instrument was tried to be used by using a different network operator between the device and the receiving cellphone. It can be seen that the results of receiving location are still faster than receiving images. The average time when using a different operator network is a little slower, which is 0.96 seconds for sending a location, and 12.09 seconds for sending a picture. This is normal and fairly common compared to the same operator network. 
Table 5. Experiment results to show the length of time needed by telegram when receiving locations using the different network between device and the receiving cellphone

\begin{tabular}{cc}
\hline Experiment & Time (second) \\
\hline 1 & 0.90 \\
2 & 0.89 \\
3 & 0.99 \\
4 & 0.92 \\
5 & 0.88 \\
6 & 0.96 \\
7 & 1.00 \\
8 & 1.22 \\
9 & 0.99 \\
10 & 0.89 \\
The average time of location & 0.96 \\
\hline
\end{tabular}

Table 6. Experiment results to show the length of time needed by telegram when receiving images using the different network between device and the receiving cellphone

\begin{tabular}{cc}
\hline Experiment & Time (second) \\
\hline 1 & 11.90 \\
2 & 12.00 \\
3 & 12.22 \\
4 & 11.97 \\
5 & 12.31 \\
6 & 12.40 \\
7 & 11.98 \\
8 & 12.99 \\
9 & 11.20 \\
10 & 11.97 \\
The average time of location & 12.09
\end{tabular}

Furthermore, the test is carried out based on the distance between the device and the parent's cellphone. Namely the selection of distances ranging from 3 kilometers to 7 kilometers. This distance choice was chosen because children used to order online transportation with this range. And testing was carried out 10 times. The results are as in Table 7 that is, the average delivery location is $98.4 \%$, and the average image delivery result is $100 \%$. And it can also be seen in the table that distance does not affect the accuracy of location or image delivery.

Table 7. Experiment results to show the success of location and figure acceptance based on distance

\begin{tabular}{cccccc}
\hline Experimen & Distance $(\mathrm{Km})$ & Sending Location & Sending Images & \multicolumn{2}{c}{ Success Rate $(\%)$} \\
& & & & Sending Location & Sending Image \\
\hline 1 & 3 & OK & OK & 100 & 100 \\
2 & 3 & OK & OK & 90 & 100 \\
3 & 4 & OK & OK & 100 & 100 \\
4 & 4 & OK & OK & 100 & 100 \\
5 & 5 & OK & OK & 97 & 100 \\
6 & 5 & OK & OK & 100 & 100 \\
7 & 6 & OK & OK & 100 & 100 \\
8 & 6 & OK & OK & 100 & 100 \\
9 & 7 & OK & OK & 100 & 100 \\
10 & 7 & OK & OK & 97 & 100 \\
\hline
\end{tabular}

\section{CONCLUSION}

This safety device for children that can be used in online transportation is perfect for children today. In addition to the low cost of manufacture, the speed of sending locations accompanied by images of the perpetrator via the telegram application is also relatively fast, 0.91 seconds and 11.57 seconds respectively using the same network between the device and the receiving cellphone. While using a different network between the device and the receiving cellphone, the speed of sending the location is 0.96 seconds, and the speed of sending images is 12.09 seconds. It also uses the latest technology, IoT, the GPS module and camera for development. This tool has a high accuracy of $97.5 \%$ for location delivery, and has an accuracy of $100 \%$ for sending images. This tool provides a very high contribution because currently online transportation is widely used by children due to the busyness of parents. Thus, besides being able to monitor children on 
online transportation, it will also be able to easily detect if something is dangerous. The situation of the child and the offender will be easily identified. In addition, if this tool is mass-produced, it will not be confused with one another because there is a telegram ID database that is entered into each device, therefore making a high contribution to society. The further research can use AIoT technology with the hope of getting shorter time and improving the camera application so that the image results are always accurate, the image quality is better, and the delivery of the location point is accurate up to $100 \%$. Also other more sophisticated technologies in the future can be used for the perfection of this tool, if it is mass-produced.

\section{REFERENCES}

[1] Kumar, D. and Anggarwal, S, "Analisis of Woman Safety in Indian Cities Using Machine Learning on Tweets," Amity International Conference on Artificial Intelligence, vol. 1, pp. 159-162, 2019, doi: 10.1109/AICAI.2019.8701247.

[2] Sharma, V., Tomar, Y., and Vydeki, D, "Smart Shoe for Women Safety," International Conference on Awareness Science and Technology, vol. 10, pp. 353-356, 2019, doi: 10.1109/ICAwST.2019.8923204.

[3] Sogi, N. R., Chatterjee, P., U Nethra, and V Suma, "SMARISA: A Raspberry Pi based Smart Ring for Woman Safety Using IoT", International Conference on Inventive Research in Computing Applications (ICIRCA), vol. 4, pp. 451-454, 2018, doi.: 10.1109/ICIRCA.2018.8597424.

[4] Ahir, S., Kapadia, S., Chauhan, J., and Sanghavi, N, "The Personal Stun-A Smart Device for Women's Safety," International Conference on Smart City and Emerging Technology, vol. 2, pp. 331-333, 2018, doi: 10.1109/ICSCET.2018.8537376.

[5] Seth, D., Chowdhury, A., and Ghosh, S, "A Hidden Markov Model and Internet of Things Hybrid Based Smart Women safety Device," International Conference on Power, Energy, and Environment: Towards Smart Technology, vol. 6, pp. 414-419, 2018, doi: 10.1109/EPETSG.2018.8658848.

[6] Muskan, Khandelwal, T., Khandelwal, M., and Pandey, P. S, "Women Safety Device Designed using IoT Machine Learning," Smart World, Ubiquitous Intelligence \& Computing, Advanced \& Trusted Computing, Scalable Computing \& Communications, Cloud \& Big Data Computing, Internet of people and Smart City Innovations, vol. 978, pp. 1204-1211, 2018, doi: 10.1109/SmartWorld.2018.00210.

[7] Viswanath, N., Pakyala, N. V., and G. Muneeswari, "Smart Foot Device for Women Safety," Symposium, IEEE, 2016, doi: 10.1109/TENCONSpring.2016.7519391.

[8] Patel, J. and Hasan, R, "Smart Bracelets: Towards Automating Personal safety using Wearable Smart Jewelry," Annual Consumer Communications \& Networking Conference, vol. 15, pp. 384-385, 2018, doi: 10.1109/CCNC.2018.8319327.

[9] Hussain, S. M., Nizamuddin, S. A., Asuncion, R., Ramaiah, C., and Singh, A. V, "Prototype of an Intelligent System based on RFID and GPS Technologies for Women Safety," International Conference on Reliability, Infocom Technologies and Optimization, vol. 5, pp. 387-390, 2016, doi: 10.1109/ICRITO.2016.7784986.

[10] Ngan Nguyen, Q. C. Nguyen, and Minh Thuy Le, "A Novel Autonomous Wireless Sensor Node for IoT Applications," TELKOMNIKA (Telecommunication Computing Electronics and Control), vol. 17, no. 5, pp. 23892399, 2019, doi: 10.12928/telkomnika.v17i5.12811.

[11] R. R. Adiputra, et al., "Internet of Things: Low Cost and Wearable SpO2 Device for Health Monitoring," International Journal of Electrical and Computer Engineering (IJECE), vol. 8, no. 2, pp. 939-945, 2018, doi: 10.11591/ijece.v8i2.pp939-945.

[12] K. Ashton, “That 'Internet of Things' Thing,” RFID Journal, vol. 22, no. 7, pp. 97-114, 2009.

[13] L. Atzori, A. Iera, and G. Morabito, "The Internet of Things: A Survey," Computer Networks, vol. 54, no. 15, pp. 2787-2805, 2010, doi: 10.1016/j.comnet.2010.05.010.

[14] Li, NI, "A New Methodology to Support Group decision-Making for IoT-Based Emergency Response Systems," Information Systems Frontiers, vol. 16, no. 5, pp. 953-977, 2014, doi: 10.1007/s10796-013-9407-z.

[15] Bianchi, V, et al., "IoT Wearable Sensor and Deep Learning: an Integrated Approach for Personalized Human Activity recognition in Smart Home Environment," Internet of Things Journal, vol. 5, pp. 289-298, 2019, doi: 10.1109/JIOT.2019.2920283.

[16] K. K. Patel and S. M. Patel, "Internet of Things-IOT: Definition, Characteristics, Architecture, Enabling Technologies, Application \& Future Challenges," International Journal of Engineering Science and Computing, vol. 6, no. 4, pp. 6122-6131, 2016.

[17] M. Maksimović, et al., "Raspberry Pi as Internet of Things hardware: Performances and Constraints," Proc.of 1s Int. Conf. on Electrical, Electronic and Computing Engineering, vol. 6, pp. 1-6, 2014, doi: 10.1145/3059009.3059028.

[18] H. K. Merchant and D. D. Ahire, "Industrial Automation using IoT with Raspberry Pi," International Journal of Computer Applications (0975-8887), vol. 168, no. 1, pp. 44-48, 2017, doi: 10.5120/ijca2017914277.

[19] T. Chakraborty and S. Kanti Datta, "Automation Using Edge Computing and Internet of Things," Proc. Int. Symposium on Consumer Electronics (ISCE), pp. 47-49, 2017, doi: 10.1109/ISCE.2017.8355544.

[20] Rony Baskoro L and Cahya Lukito, "Development of IoT hydroponic system using Raspberry Pi," TELKOMNIKA (Telecommunication Computing Electronics and Control), vol. 17, no. 2, pp. 897-906, 2019, doi: 10.12928/telkomnika.v17i2.9265.

[21] J. Muthna, R. A. Fayadh, M. Fadhil, and M. K. Wali, "Design and Implementation of Smart Electronic Solar Tracker Based on Arduino," TELKOMNIKA (Telecommunication Computing Electronics and Control), vol. 17, no. 5, pp. 2486-2496, 2019, doi: 10.12928/telkomnika.v17i5.10912. 
[22] W. F. Abaya, J. Basa, M. Sy, A. C. Abad, and E. P. Dadios, "Low Cost Smart Security Camera with Night Vision Capability Using Raspberry $\mathrm{Pi}$ and OpenCV," International Conference on Humanoid, Nanotechnology, Information Technology, Communication and Control, Environment and Management (HNICEM), Palawan, pp. 16, 2014, doi: 10.1109/HNICEM.2014.7016253.

[23] Siliya, Y. and Haddadi, H, "New Directions in Jewelry: A Close Look at Emerging Trends; Developments in Jewelry-like Wearable devices," Proceeding of the 2015 ACM International Symposium on Wearable Computers, vol. 15, pp. 49-56, 2015, doi: 10.1145/2802083.2808410.

[24] Romano, Marco, "Designing Mobile Applications for Emergency Response: Citisens Acting as Human Sensors," Sensors, vol. 16, no. 3, pp. 406-413, 2016, doi: 10.3390/s16030406.

[25] Cannon C, "Telehealth, Mobile Applications, and Wearable Devices are Expanding Cancer Care beyond Walls," Seminars in Oncology Nursing, vol. 34, no. 2, pp. 118-125, 2018, doi: 10.1016/j.soncn.2018.03.002.

[26] Chan, M., Esteve, D., Fourniols, J. Y., Escriba, C., and Campo, E, "Smart Wearable Systems: Current Status and Future Challanges," Artificial Intelligence in Medicine, vol. 56, no. 2, pp. 137-156, 2012, doi: 10.1016/j.artmed.2012.09.003.

[27] K. A. Mohd Annuar, M. F. Maharam, N. A. Hadi, M. H. Harun, A. B. Halim, "Development of wireless and intelligent home automation system," TELKOMNIKA (Telecommunication Computing Electronics and Control), vol. 17, no. 1, pp. 32-38, 2019, doi: 10.12928/telkomnika.v17i1.9075.

[28] Paradkar, Abhijit, and Sharma, D, “All in one Intelligent Safety,” Region Humanitory Technology Conference, vol. 10, pp. 441-443, 2015, doi: 10.5120/ijca2015907144.

[29] S. Isaak, et al., "A Low Cost Spectroscopy with Raspberry Pi for soil Macronutrient Monitoring," TELKOMNIKA (Telecommunication Computing Electronics and Control), vol. 17, no. 4, pp. 1867-1873, 2019, doi: 10.12928/telkomnika.v17i4.12775.

\section{BIOGRAPHIES OF AUTHORS}

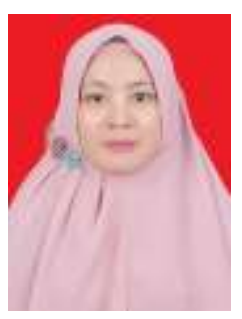

Elsyea Adia Tunggadewi, her field is telecommunications, networks, antennas and electrical. She is lecturer in Department of Engineering, Universitas Airlangga (2018-now). She was graduated of Bachelor degree from Brawijaya University in 2009 and graduated of Master Degree from Institut Teknologi Sepuluh Nopember in 2012.

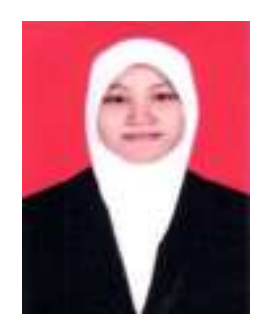

Eva Inaiyah Agustin, her field is analog circuits, electronics, electronic sensors, and signals. She is lecturer in Department of Engineering, Universitas Airlangga (2016-now). She was graduated of Bachelor degree from PENS in 2013 and graduated of Master Degree from Institut Teknologi Sepuluh Nopember in 2015.

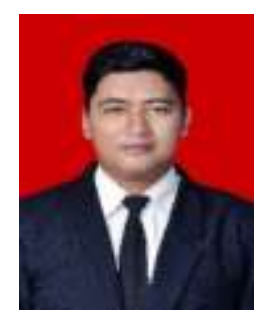

Riky Tri Yunardi, his field is electronics, robotics and computer vision. He is lecturer in Department of Engineering, Universitas Airlangga (2015-now). He was graduated of Bachelor degree from Brawijaya University in 2011 and graduated of Master Degree from Institut Teknologi Sepuluh Nopember in 2014. He is currently member of Institute Electrical and Electronics Engineering. 